Vol.: 5 Issue: 2 Date: 31.12.2021 Received: 31.08.2021 Accepted: 13.11.2021 Final Version: 31.12.2021

ISVOS Journal, 2021, 5(2): 115-123 - https://doi.org/10.47897/bilmes.989082

\title{
Hydrological Drought Analysis for Bolu City with Streamflow Drought Index
}

\author{
Onur Arslan ${ }^{\mathrm{a}, 1}$ \\ aBolu Abant İzzet Baysal University, Department of Civil Engineering, Bolu, Turkey \\ ORCID ID: 0000-0003-2456-1788
}

\begin{abstract}
Hydrological drought refers to the decrease in the amount of water found in surface or groundwater resources and monitoring of this natural disaster is very important due to causing serious problems in drinking and irrigation water supply and hydroelectric energy production. In this study, hydrological drought analysis was made for two streams in Bolu city located in the Western Black Sea Region in the north of Turkey and 3, 6 and 12 month streamflow drought indices were calculated by using the Streamflow Drought Index method. For this aim, the streamflow data of Bolu stream - Beşdeğirmen and Ulusu - Afatlar streamflow monitoring stations were used. According to the results, extreme and severe droughts were determined for two stream flow stations and it is seen that drought periods varied between 1 and 9 years. The most severe and longest droughts were detected for Bolu stream - Beşdeğirmen station. Mild droughts are much higher than moderate, severe and extreme droughts. It has been observed that the severity and number of drought for Bolu stream - Beşdeğirmen station have increased in recent years. In order to reduce the effects of hydrological drought, hydrological drought should be monitored continuously and necessary precautions should be taken regarding the management of water resources. People should be informed about water consumption and so waste should be prevented. In terms of irrigation water, drip irrigation method should be used instead of flood irrigation or sprinkler irrigation methods. For this aim, farmers should be made aware of this issue. Alternative renewable energy sources or other energy sources should be used for reductions in hydroelectric energy production.
\end{abstract}

Keywords:" Streamflow Drought Index, Drought, Bolu."

\section{Giriș}

Meteorolojik, tarımsal, hidrolojik ve sosyo-ekonomik gibi sınıflara ayrılarak incelenen kuraklık, etkileri son derece yıkıcı olan ve bu nedenle sürekli izlenmesi gereken doğal bir afettir. Meteorolojik kuraklık yağış miktarlarındaki, tarımsal kuraklık ise zemin nemindeki azalma sonucu ortaya çıkan kuraklıklardır. Hidrolojik kuraklık ise akarsu akım miktarlarındaki azalma ya da göl, baraj gölü gibi yüzeysel su kaynakları ile yeraltı su kaynaklarındaki seviye düşmesi sonucu ile meydana gelen kuraklıktır. Buradaki azalma ya da seviye düşmesi genellikle uzun yıllar ortalaması dikkate alınarak belirlenmekte olup uzun bir süre boyunca devam edebilir. Sosyo-ekonomik kuraklık ise yaşanan kuraklıklar ile bağlantılı olarak sosyal ve ekonomik yaşamda meydana gelen olumsuzluklarla kendini gösteren kuraklıktır.

Hidrolojik kuraklık birçok olumsuz etkiye neden olmaktadır. Akarsulardaki su miktarının azalması durumunda doğal göllerimizdeki ya da çeşitli amaçlar için kullanılan barajlarda ciddi sorunlar yaşanabilir. İçme suyu ihtiyacını karşılayan barajlardaki su seviyesinin azalması sonucunda içme suyu sıkıntısı ortaya çıkabilir. Tarımsal sulama amaçlı barajlardaki su seviyesinin azalması sonucunda tarımda sulama suyu sıkıntısı oluşabilir. Hidroelektrik enerji üretimi yapılan barajlardaki su seviyesinin azalması sonucunda hidroelektrik enerji üretiminde azalma yaşanabilir. İçme veya sulama amaçlı yeraltı suyunun kullanıldığı yerlerde yeraltı su seviyesi daha da düşebilir. Ulaşım amaçlı kullanılan nehirlerde ulaşım yapılamayabilir. Turizm ve rekreasyon amaçlı kullanılan göller hidrolojik kuraklık sonucunda tamamen kuruyabilirler. Tüm bu nedenlerle su kaynaklarının projelendirilmesi ile etkin ve sürdürülebilir yönetiminin gerçekleştirilmesi açısından hidrolojik kuraklığın izlenmesi ve kuraklık durumuna göre gerekli önlemlerin alınması gereklidir.

Dünyanın çeşitli bölgelerinde hidrolojik kuraklığı araştırmak amacıyla çeşitli çalışmalar yapılmıştır. Tabari ve ark. Kuzeybatı İran için [1], Zhao ve ark. Çin'deki Jinghe Nehri Havzası için [2], Hong ve ark. Çin'deki Yukarı Yangtze Nehir Havzası için [3], Akbari ve ark. İran'daki Chenar Rahdar havzası için [4], Zhiyong ve ark. Xijiang Nehri Havzası için [5], Won ve ark. Kore'nin Cheongmicheon havzası için [6], Fendeková ve ark. Slovakya için [7] hidrolojik kuraklık analizi yapmışlardır.

${ }^{1}$ Sorumlu Yazar. Tel.: +90-374-254-1000/4945 ; fax: +090-374-253-4548 .

E-posta adresi: onarslansdu@ @otmail.com 
Ülkemizde de hidrolojik kuraklığı araştırmak amacıyla çeşitli çalışmalar yapılmıştır. Gümüş Asi havzası için [8], Gümüş ve Algin Seyhan-Ceyhan Nehir Havzaları için [9], Özfidaner ve ark. Seyhan Havzası için [10], Yıldız Fırat Havzası için [11], Erogluer ve Apaydın Ankara Nallıhan için [12] hidrolojik kuraklık analizi yapmıştır. Yapılan bu çalışmalarda ciddi hidrolojik kuraklıklar tespit edilmiştir.

Bu çalışmada Bolu ilindeki eksiksiz akım verisine sahip iki akım gözlem istasyonunun akım verileri ve akım kuraklık indeksi kullanılarak hidrolojik kuraklık analizi yapılmıştır.

\section{Materyal ve Metot}

\section{1. Çalışma Alanı ve Veriler}

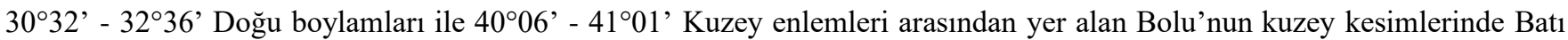
Karadeniz iklimi görülüyor iken güney kesimlerinde İç Anadolu iklimi görülmektedir. Ortalama $1000 \mathrm{~m}$ yükseltide bulunan Bolu 34.336 hektarı sulu ve 83.794 hektarı kuru olmak üzere 118.130 hektar tarım alanına sahiptir. Bu alan Bolu'nun \% 15'ine ve Türkiye tarım alanlarının \% 0,5' ine karşılık gelmektedir [13]. TUİK verilerine göre 2020 yılı nüfusu 314 bin 802 kişidir.

Bolu ili Batı Karadeniz ve Sakarya havzaları üzerinde yer almaktadır. Bu çalışmada Bolu'nun Batı Karadeniz Havzası'nda bulunan, eksiksiz akım verisi sahip ve Şekil 1'de gösterilen iki akım gözlem istasyonuna ait veriler kullanılmıştır. Batı Karadeniz Havzası'nda bulunan diğer akım gözlem istasyonları ile Sakarya Havzası içerisindeki akım gözlem istasyonlarına ait akım verilerinde eksiklikler olduğundan bu çalışmada kullanılmamıştır. Bu çalışmada kullanılan iki akım gözlem istasyonunun akım verileri Devlet Su İşleri'nden temin edilmiş olup kullanılan akım gözlem istasyonlarına ait bilgiler Tablo 1'de ve akım verileri ise Şekil 2'de verilmiştir.

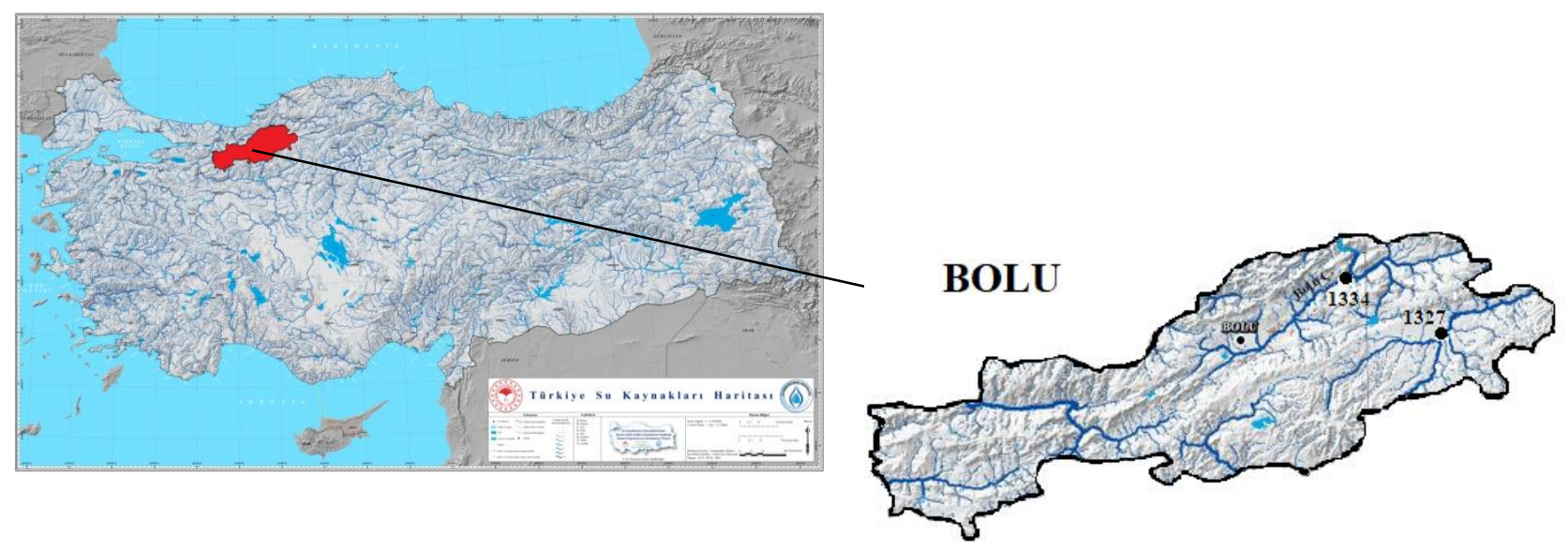

Şekil 1. Türkiye su kaynakları haritası [14] ve çalışmada kullanılan Bolu İli’ndeki akım gözlem istasyonların yerleri.

Tablo 1. Akım gözlem istasyonlarına ait bilgiler

\begin{tabular}{llll}
\hline No & Adı & Konumu & İncelenen dönem \\
\hline 1334 & Bolu Çayı - Beşdeğirmen & $31^{\circ} 55^{\prime} 48^{\prime \prime}$ D - 40 53' 12" K & $1982-2011$ \\
1327 & Ulusu - Afatlar & $32^{\circ} 15^{\prime}$ 03" D - 40 44' 32" K & $1982-2011$ \\
\hline
\end{tabular}
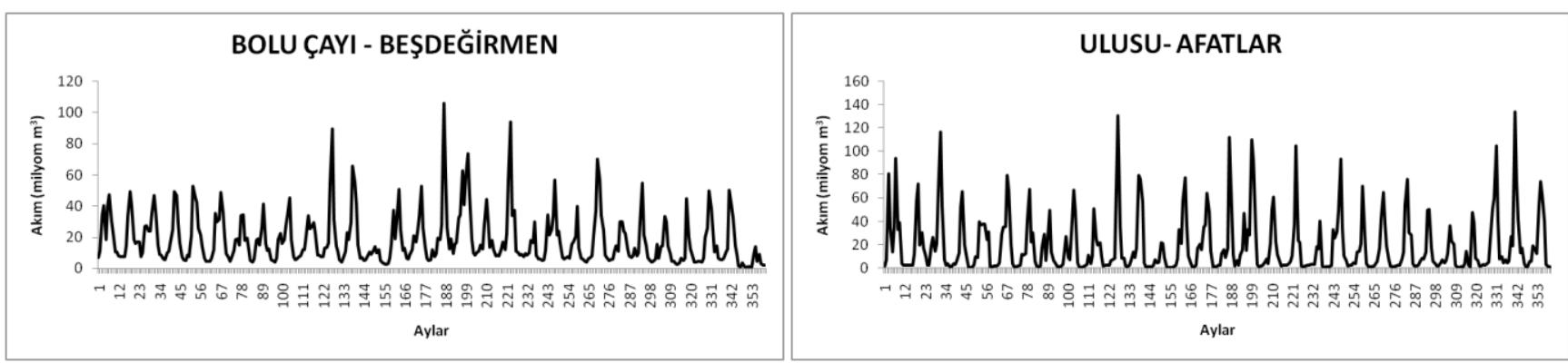

Şekil 2. Çalışmada kullanılan akım gözlem istasyonlarına ait akım verileri. 


\subsection{Akım Kuraklık İndisi}

Akarsuların aylık akım verilerinin kullanıldığı ve 3, 6, 9 ve 12 aylık olmak üzere farklı periyotlar için hidrolojik kuraklık değerlendirmesinin yapılabildiği bu yöntem Nalbantis [15] tarafından geliştirilmiştir. Kuraklık indisi Eşitlik 1, 2, 3 ve 4 kullanılarak hesaplanmaktadır.

$$
\begin{gathered}
V_{i, k}=\sum_{j=3(k-1)+1}^{3 k} Q_{i, j}, k=1,2,3,4 \\
V_{i, k}=\sum_{j=6(k-1)+1}^{6 k} Q_{i, j}, k=1,2 \\
V_{i, k}=\sum_{j=1}^{12} Q_{i, j} \\
A K \dot{\mathrm{I}}_{i, k}=\frac{V_{i, k}-\overline{V_{k}}}{S_{k}}, k=1,2,3,4
\end{gathered}
$$

Burada i hidrolojik yılı, j Ekim ayından başlayıp Eylül ayında son bulan hidrolojik yıla ait ayı, $\mathrm{V}_{\mathrm{i}, \mathrm{k}} \mathrm{i}$ 'inci hidrolojik yılın k'ıncı referans periyoduna ait kümülatif akım hacmini $\left(\mathrm{m}^{3}\right), \overline{V_{k}}$ kümülatif hacmin ortalamasını $\left(\mathrm{m}^{3}\right), \mathrm{S}_{\mathrm{k}}$ kümülatif hacmin standart sapmasını $\left(\mathrm{m}^{3}\right)$ ve $A K \dot{I}_{\mathrm{i}, \mathrm{k}} \mathrm{i}$ 'inci hidrolojik yılın k'ıncı referans periyoduna ait akım kuraklık indisini göstermektedir. Eşitlik 1'de k=1 olduğunda Ekim-Aralık dönemi AKİ 3 Ekim olarak, k=2 olduğunda Ocak-Mart dönemi AKİ 3 Ocak olarak, k=3 olduğunda Nisan-Haziran dönemi AKİ 3 Nisan olarak, k=4 olduğunda Temmuz-Eylül dönemi AKİ 3 Temmuz olarak ifade edilmektedir. Eşitlik 2'de k=1 olduğunda Ekim-Mart dönemi AKİ 6 Ekim olarak, k=2 olduğunda Nisan-Eylül dönemi AKİ 6 Nisan olarak ifade edilmektedir. Eşitlik 3'te k değeri olmayıp Ekim-Aralık dönemi AKİ 12 Ekim olarak ifade edilmektedir. Yöntemde AKİ değerlerine göre 4 kuraklık ve 4 nemlilik olmak üzere 8 sınıf bulunmakta olup bu sınıflar Tablo 2'de verilmiştir.

Tablo 2. AKİ Değerlerine ilişkin sınıflandırma [3]

\begin{tabular}{ll}
\hline AKI & Sınıflandırma \\
\hline AKI $\leq-2$ & Aşırı Kurak (AK) \\
$-2<\mathrm{AKI} \leq-1,5$ & Şiddetli Kurak (ŞK) \\
$-1,5<\mathrm{AKI} \leq-1$ & Orta Kurak (OK) \\
$-1<\mathrm{AKI} \leq 0$ & Hafif Kurak (HK) \\
$0<\mathrm{AKI} \leq 1$ & Hafif Nemli (HN) \\
$1<\mathrm{AKI} \leq 1,5$ & Orta Nemli (ON) \\
$1,5<\mathrm{AKI} \leq 2$ & Şiddetli Nemli (ŞN) \\
$1 \mathrm{AKI} \geq 2$ & Aşırı Nemli (AN) \\
\hline
\end{tabular}

\section{Bulgular ve Tartışma}

Bolu Çayı Beşdeğirmen istasyonu akım değerleri kullanılarak hesaplanmış 3, 6 ve 12 aylık AKİ değerleri Şekil 3' te verilmiştir. En şiddetli kuraklıklar AKİ 3 Ekim için -3,43 değeri ve AKİ 3 Ocak için -3,46 değeri ile 2011 yılında, AKİ 3 Nisan için -1,92 değeri ile 1994 yılında, AKİ 3 Temmuz için -2,22 değeri ile 2010 yılında, AKİ 6 Ekim için -3,82 değeri ve AKİ 6 Nisan için -2,01 değeri ve AKİ 12 Ekim için -3,17 değeri ile 2011 yılında yaşanmıştır. Tüm bu değerler AKİ 3 Nisan hariç aşırı kurak sınıfina girmektedir ve çoğu 2011 yılında gerçekleşmiştir. En nemli durumlar ise AKİ 3 Ekim için 1,77 değeri ile 1984 yılında, AKİ 3 Ocak için 1,57 değeri ile 1986 yılında, AKİ 3 Nisan için 2,17 değeri ile 1997 yılında, AKİ 3 Temmuz için 1,75 değeri ile 1983 yılında, AKİ 6 Ekim için 1,73 değeri ile 1998 yılında, AKİ 6 Nisan için 2,17 değeri ile 1997 yılında ve AKİ 12 Ekim için 2,04 değeri ile 1998 yılında yaşanmıştır. Tüm bu değerler 1998 yılından önce gerçekleşmiş olup AKİ 3 Nisan ve AKİ 6 Nisan hariç şiddetli nemli sınıfına girmektedir. Şekil 3'teki grafikler incelendiğinde tüm periyotlar için hidrolojik kuraklık sayısının, süresinin ve şiddetinin son yıllara doğru arttığı görülmüştür. 

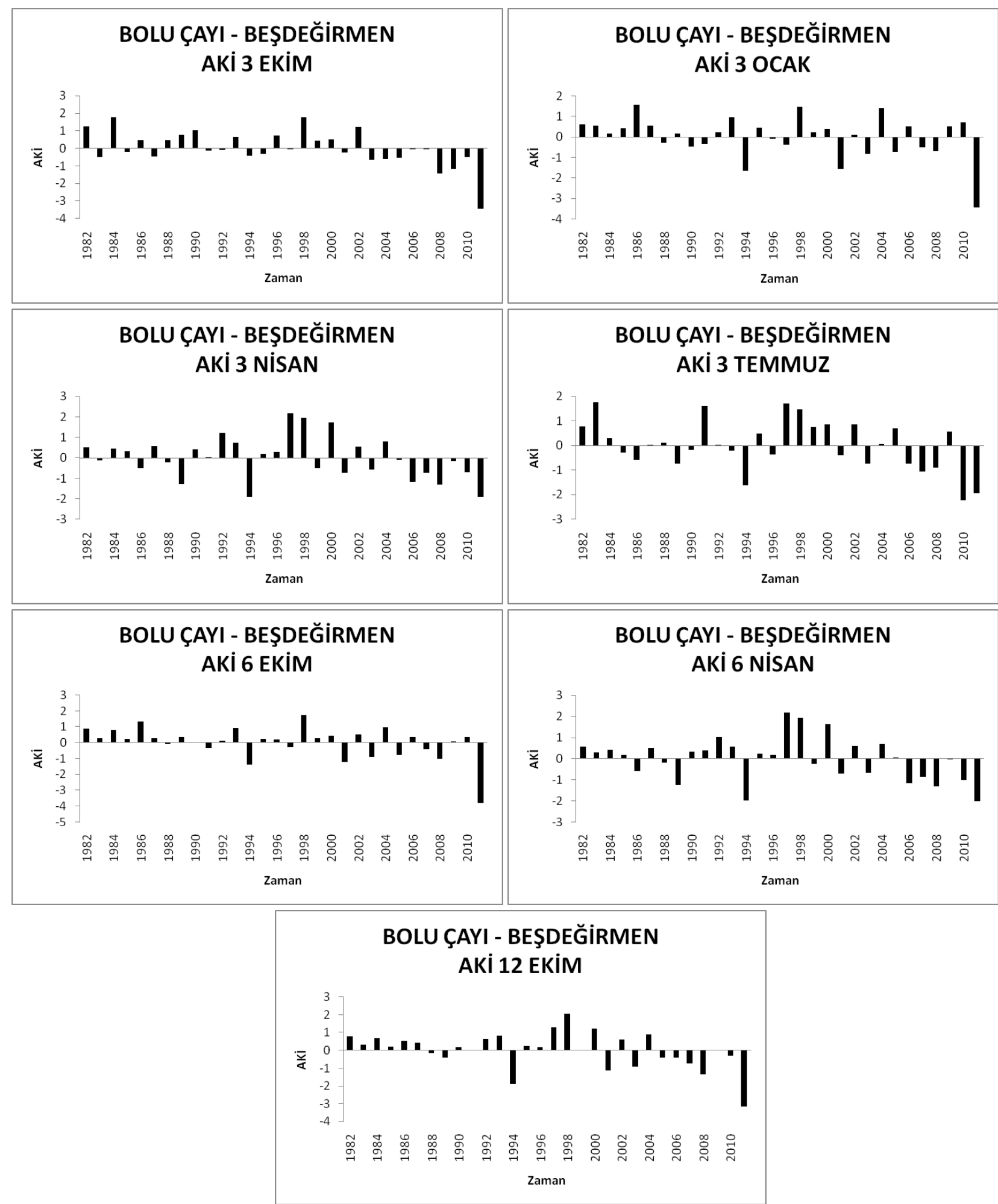

Şekil 3.Bolu Çayı Beşdeğirmen istasyonunu akım değerleri için hesaplanmış AKİ değerleri.

Bolu Çayı Beşdeğirmen istasyonu AKİ değerleri kullanılarak hesaplanan hafif, orta, şiddetli, aşırı ve toplam nemlilik ve kuraklık yüzdeleri Şekil 4'te verilmiştir. Hafif nemli dönem yüzdesinin orta, şiddetli ve çok şiddetli nemlilik yüzdelerine, hafif şiddetli kuraklık yüzdelerinin ise orta, şiddetli ve çok şiddetli kuraklık yüzdelerine göre çok daha fazla olduğu görülmüştür. Aki 3 Ekim için toplam kuraklık yüzdesi toplam nemlilik yüzdesinden daha büyüktür. AKİ 3 Nisan için yüzdeler eşitken AKİ 3 Ocak, AKİ 3 Nisan, AKİ 3 Temmuz, AKİ 6 Ekim, AKİ 6 Nisan ve AKİ 12 Ekim için yağışlı dönem yüzdesi daha büyük çıkmıştır. 


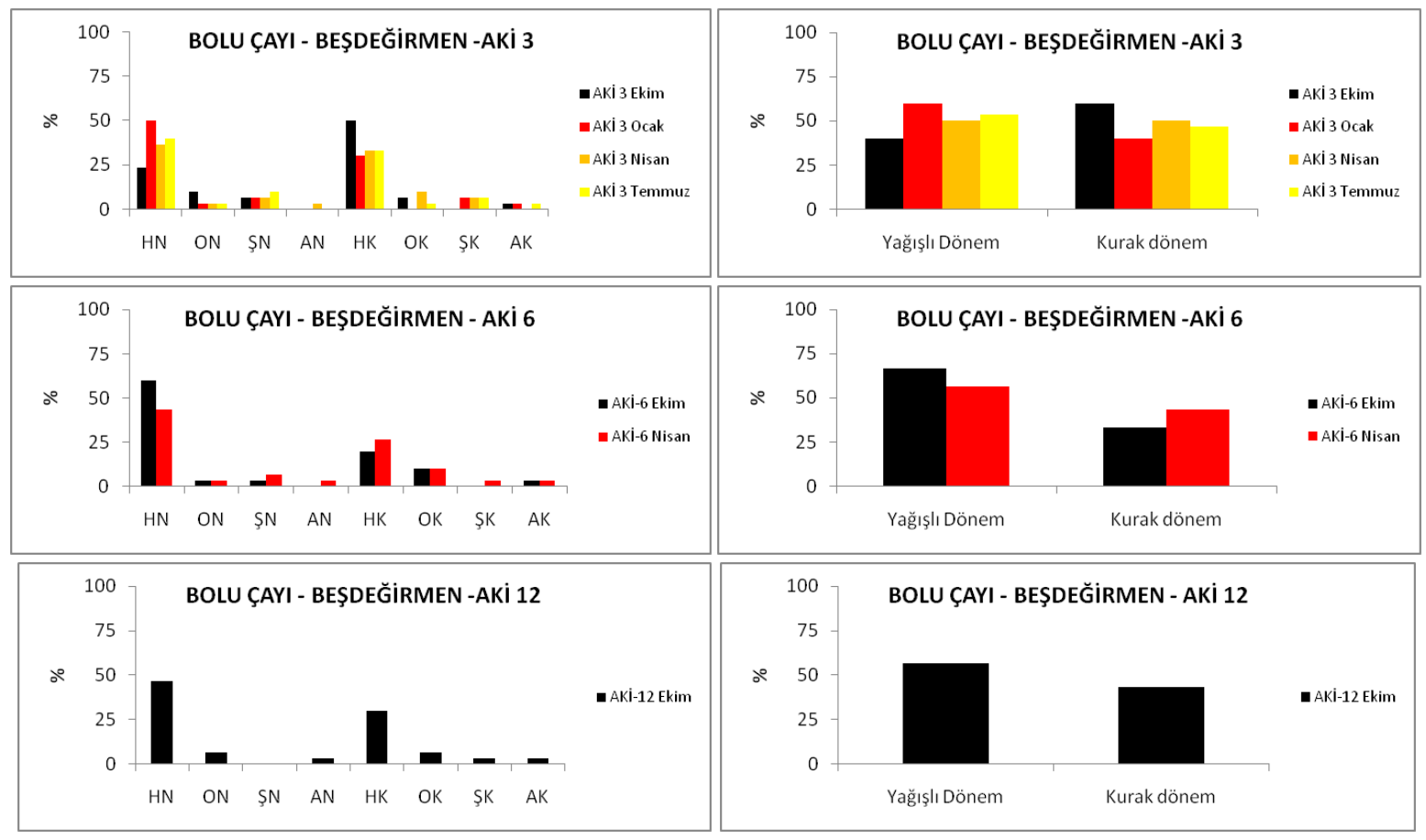

Şekil 4.Bolu Çayı Beşdeğirmen istasyonu akım değerleri için kuraklık ve nemlilik yüzdeleri.

Bolu Çayı Beşdeğirmen istasyonu için yaşanan hidrolojik kuraklık sayıları ve süreleri Şekil 5'te verilmiştir. Grafikler incelendiğinde kuraklık süreleri AKİ 3 Ekim için 1 ile 9 yıl, AKİ 3 Ocak için 1 ile 2 yıl, AKİ 3 Nisan için 1 ile 7 yıl, AKİ 3 Temmuz için 1 ile 3 yıl, AKİ 6 Ekim için 1 ile 2 yıl, AKİ 6 Nisan için 1 ile 6 yıl ve AKİ 12 Ekim için 1 ile 4 yıl arasında değişmiştir. Kısa süren kuraklıklar daha çok olmakla birlikte az da olsa 6 ile 9 yıl arasında değişen uzun süreli kuraklıklar mevcuttur.

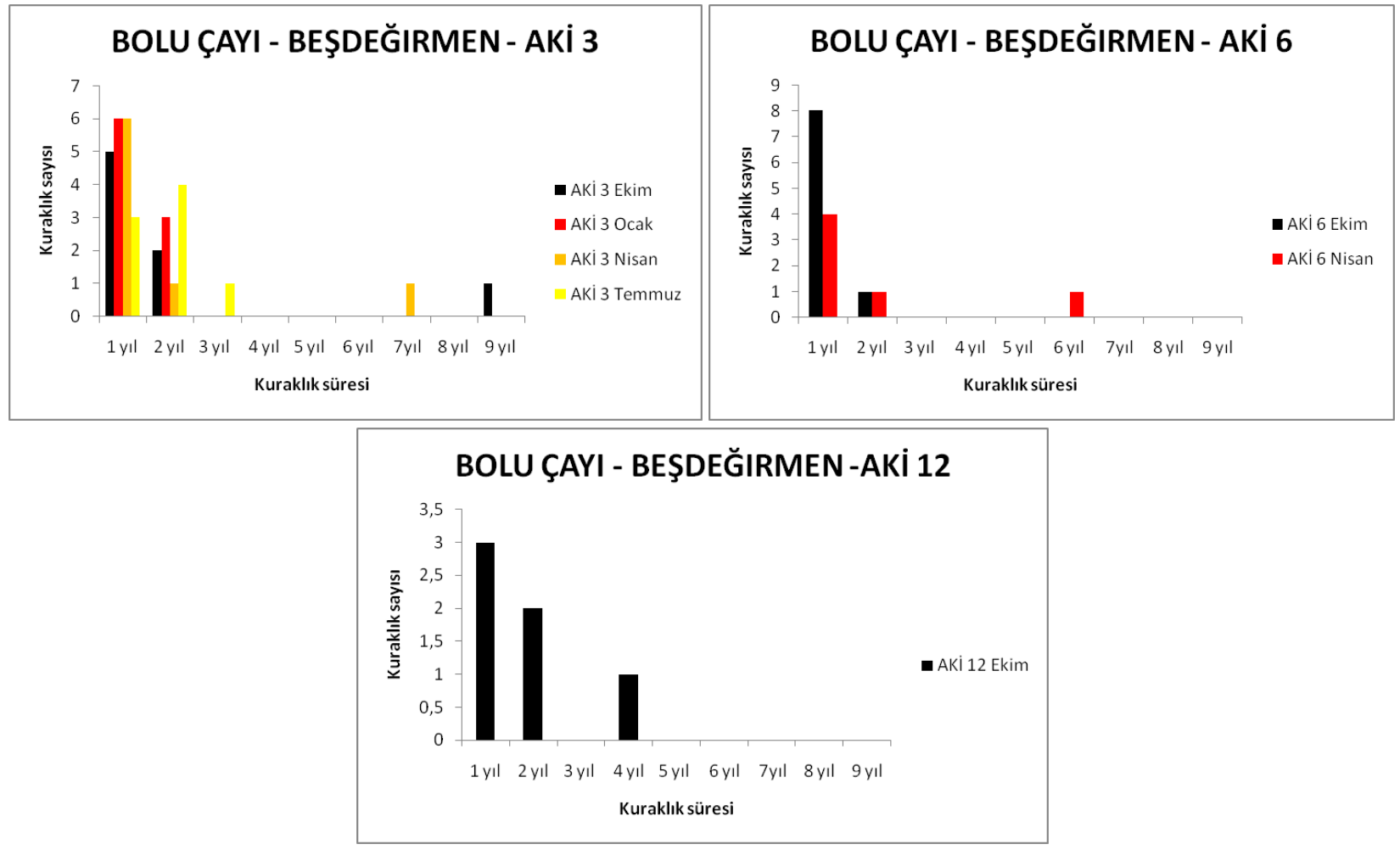

Şekil 5.Bolu Çayı Beşdeğirmen istasyonu akım değerleri için kuraklık sayıları ve süreleri.

Ulusu Afatlar istasyonu akım değerleri kullanılarak hesaplanmış 3, 6 ve 12 aylık AKİ değerleri Şekil 6' da verilmiştir. En şiddetli kuraklıklar AKİ 3 Ekim için -1,27 değeri ile 2005 yılında, AKİ 3 Ocak için -2,26 değeri ile 2001 yılında, AKİ 3 Nisan için -2,39 değeri ile 1989 yılında, AKİ 3 Temmuz için -1,79 değeri ile 1994 yılında, AKİ 6 Ekim için -2,27 değeri ile 2001 yılında, AKİ 6 Nisan için -2,37 değeri ile 1989 yılında ve AKİ 12 Ekim için -2,56 değeri ile 1994 yılında yaşanmıştır. Tüm bu değerlerin 
çoğu aşırı kurak sınıfına girmektedir. En nemli durumlar ise AKİ 3 Ekim için 2,53 değeri ile 1982 yılında, AKİ 3 Ocak için 2,98 değeri ile 2010 yılında, AKİ 3 Nisan için 1,80 değeri ile 1998 yılında, AKİ 3 Temmuz için 2,73 değeri ile 1983 yılında, AKİ 6 Ekim için 2,67 değeri ile 2010 yılında, AKİ 6 Nisan için 1,74 değeri ile 1998 yılında ve AKİ 12 Ekim için 1,74 değeri ile 1998 yılında yaşanmıştır. Tüm bu değerlerin çoğu şiddetli nemli sınıfına girmektedir. Şekil 6'daki grafikler incelendiğinde tüm periyotlar için hidrolojik kuraklık sürelerinin son yıllara doğru arttığı ancak şiddet olarak azaldığı görülmüştür.

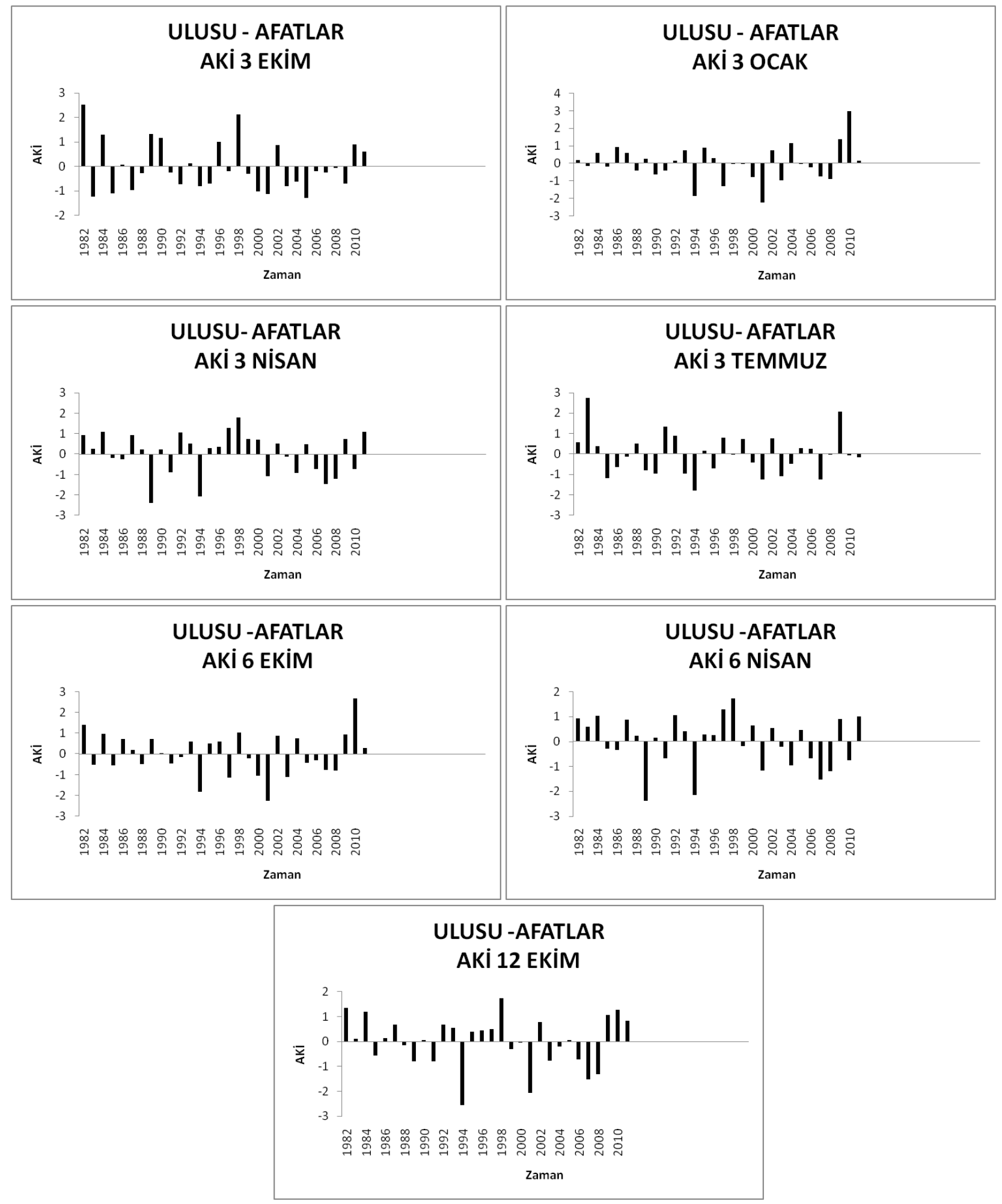

Şekil 6.Ulusu Afatlar istasyonunu akım değerleri için hesaplanmış AKİ değerleri.

Ulusu Afatlar istasyonu AKİ değerleri kullanılarak hesaplanan hafif, orta, şiddetli, aşırı ve toplam nemlilik ve kuraklık yüzdeleri Şekil 7'de verilmiştir. Hafif nemli dönem yüzdesinin orta, şiddetli ve çok şiddetli nemlilik yüzdelerine, hafif şiddetli kuraklık yüzdelerinin ise orta, şiddetli ve çok şiddetli kuraklık yüzdelerine göre çok daha fazla olduğu görülmüştür. AKİ 3 Ekim, 
AKİ 3 Ocak ve AKİ 3 Temmuz için toplam kuraklık yüzdesi toplam nemlilik yüzdesinden daha büyüktür. AKİ 6 Ekim için yüzdeler eşitken AKİ 3 Nisan, AKİ 6 Nisan ve AKİ 12 Ekim için yağışlı dönem yüzdesi daha büyük çıkmıştır.

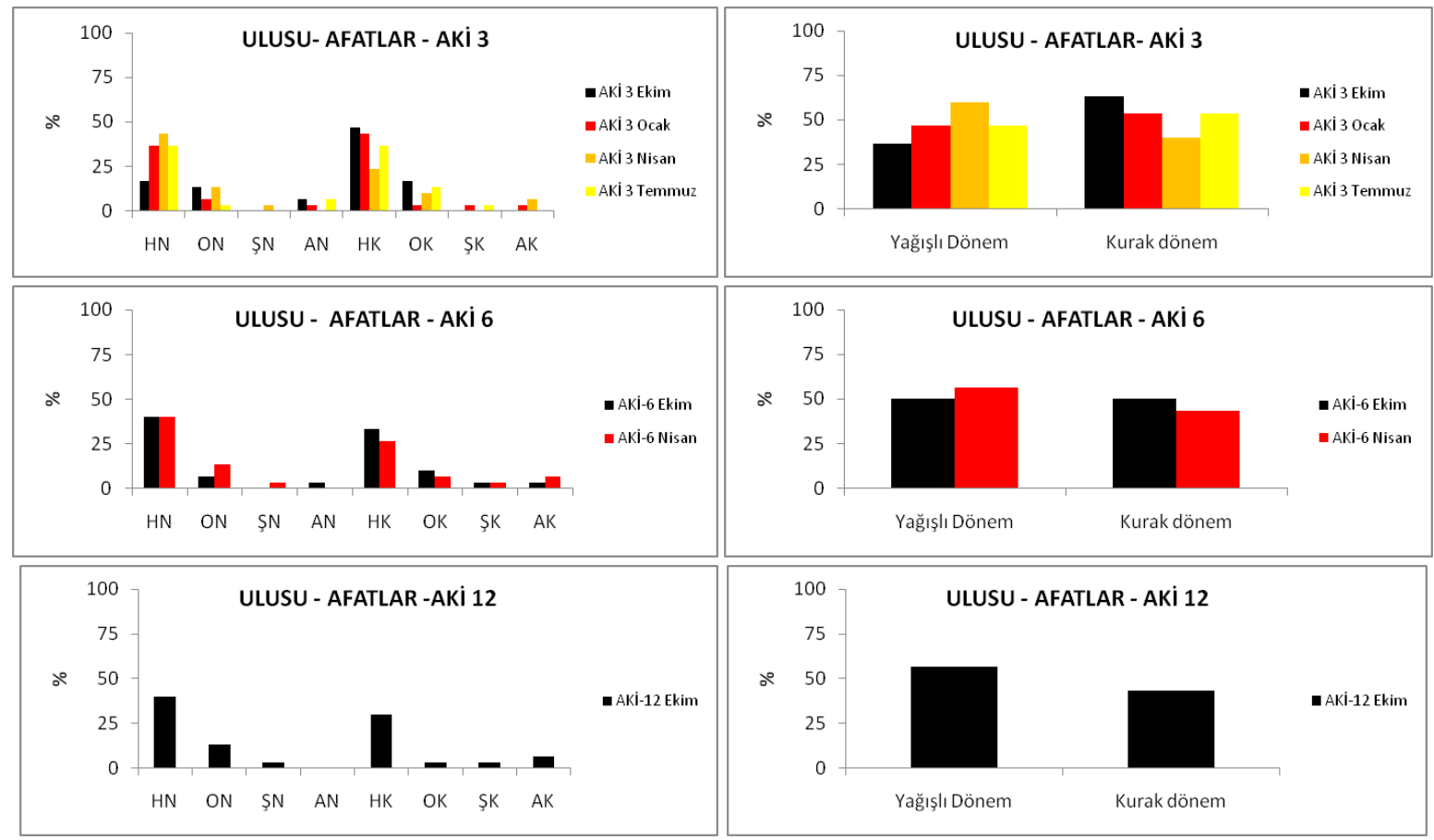

Şekil 7.Ulusu Afatlar istasyonu akım değerleri için kuraklık ve nemlilik yüzdeleri.

Ulusu Afatlar istasyonu için yaşanan hidrolojik kuraklık sayıları ve süreleri Şekil 8'de verilmiştir. Grafikler incelendiğinde kuraklık süreleri AKİ 3 Ekim için 1 ile 7 yıl, AKİ 3 Ocak için 1 ile 5 yıl, AKİ 3 Nisan ve AKİ 3 Temmuz için 1 ile 3 yıl, AKİ 6 Ekim için 1 ile 4 yıl ve AKİ 6 Nisan ve AKİ 12 Ekim için 1 ile 3 yıl arasında değişmiştir. Kısa süren kuraklıklar daha çok olmakla birlikte az da olsa 5 ile 7 yıl arasında değişen uzun süreli kuraklıklar mevcuttur.
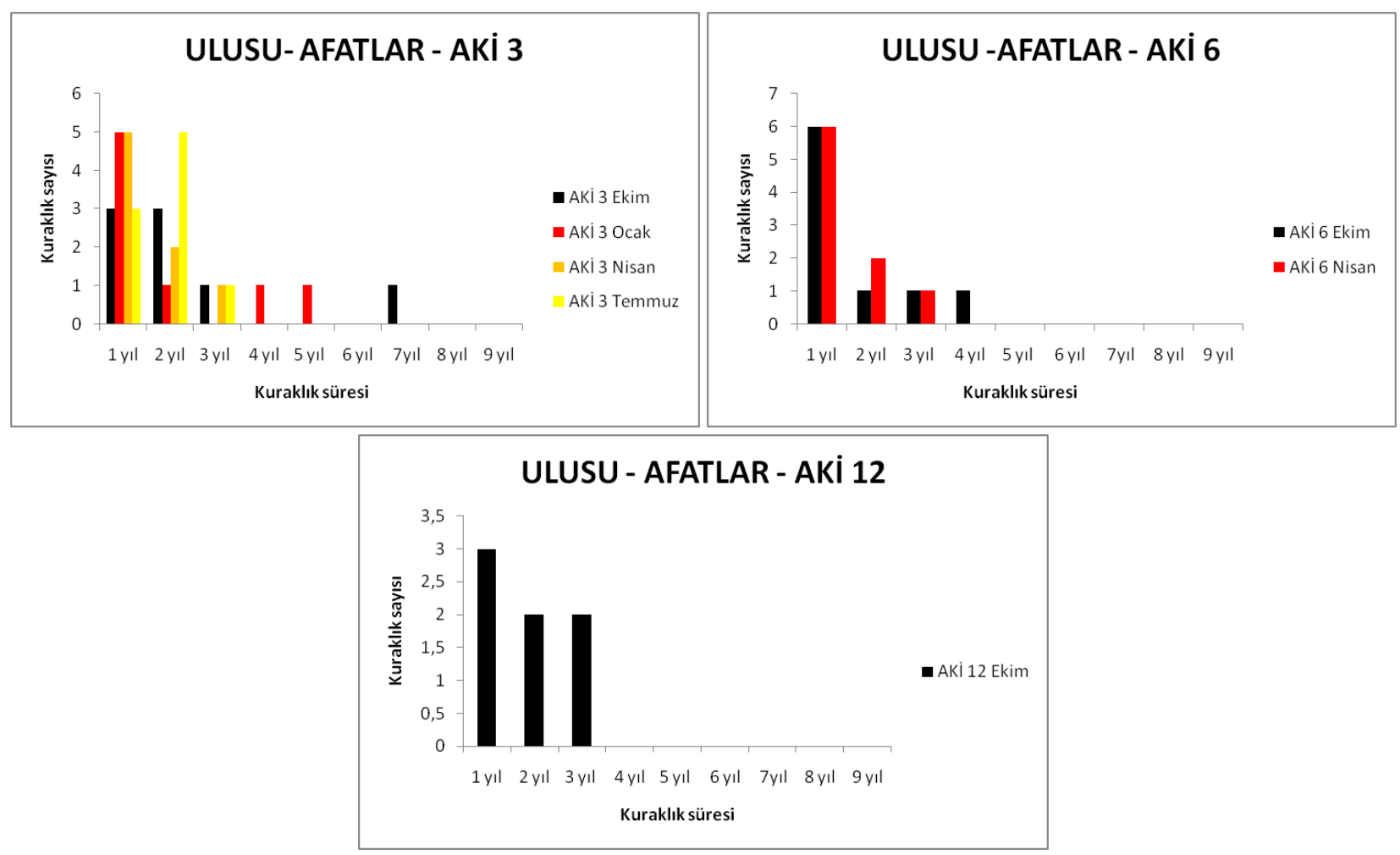

Şekil 8. Ulusu Afatlar istasyonu akım değerleri için kuraklık sayıları ve süreleri. 


\section{Sonuc}

Bu çalışmada Bolu'da eksiksiz akım verisi bulunan iki akım gözlem istasyonu verileri kullanılarak 3, 6 ve 12 aylık periyotlar için hidrolojik kuraklık analizi yapılmış ve aşağıdaki sonuçlara varılmıştır.

- Her iki akım gözlem istasyonu için aşırı ve şiddetli hidrolojik kuraklıklar tespit edilmiş olup hafif şiddetli kuraklıklar orta, şiddetli ve çok aşırı kurak durumlara göre çok daha fazladır.

- Kuraklık süreleri 1 ile 9 yıl arasında değişmektedir.

- Bolu çayı Beşdeğirmen akım gözlem istasyonunda yaşanan kuraklıklar Ulusu Afatlar akım gözlem istasyonunda yaşanan kuraklıklara göre çoğunlukla daha şiddetli ve daha uzun sürelidir.

- Bolu çayı Beşdeğirmen akım gözlem istasyonu için kuraklık şiddetinin ve sayısının son yıllarda arttığı tespit edilmiştir. En şiddetli kuraklıkların çoğu araştırma döneminin son yılı olan 2011 yılında gözlenmiştir. Ulusu Afatlar akım gözlem istasyonu için ise hidrolojik kuraklık sürelerinin son yıllara doğru arttığı ancak şiddet olarak azaldığı belirlenmiştir.

Hidrolojik kuraklığın etkilerini azaltmak amacıyla hidrolojik kuraklık devamlı olarak izlenmeli ve su kaynaklarının yönetimi ile ilgili gerekli önlemler alınmalıdır. İnsanlar kullanma suyu tüketimi konusunda bilgilendirilmeli ve israf önlenmelidir. Sulama suyu açısından salma sulama veya yağmurlama sulama yöntemleri yerine damla sulama yöntemi kullanılmalıdır ve bu konuda çiftçiler bilinçlendirilmelidir. Hidroelektrik enerji üretimi konusunda yaşanan azalmalara yönelik alternatif yenilebilir enerji kaynakları ya da diğer enerji kaynakları kullanılmalıdır.

\section{Teşekkür}

Veri temini için Devlet Su İşleri’ ne teşekkür ederim.

\section{Referanslar}

[1] H. Tabari, J. Nikbakht, P. Hosseinzadeh Talaee, P., "Hydrological Drought Assessment in Northwestern Iran Based on Streamflow Drought Index (SDI),', Water Resources Management, vol. 27, no. 1, pp. 137-151, 2013.

[2] L. Zhao, A. Lyu, J. Wu, M. Hayes, Z. Tang, B. He, M. and Liu, "Impact of Meteorological Drought on Streamflow Drought in Jinghe River Basin of China,'’ Chinese Geographical Science, vol. 24, no. 6, pp. 694-705, 2014.

[3] X. Hong, S. Guo, Y. Zhou, L. and Xiong, "Uncertainties in assessing hydrological drought using streamflow drought index for the upper Yangtze River basin," Stochastic Environmental Research and Risk Assessment, vol. 29, no. 4, pp. 1235-1247, 2014.

[4] H. Akbarı, G. R. Rakhshandehroo, A. H. Sharıfloo, and E. Ostadzadeh, "Drought Analysis Based on Standardized Precipitation Index (SPI) and Streamflow Drought Index (SDI) in Chenar Rahdar River Basin, Southern Iran," In Proceedings of the Watershed Management Symposium, 2015, pp. 11-22.

[5] Wu. Zhıyong, Lin. Qıngxıa, Lu. Guihua, He. Ha1, J. Qu John, J. “Analysis of Hydrological Drought Frequency For The Xijiang River Basin in South China Using Observed Streamflow Data,’” Nat Hazards, vol. 77, no. 1, pp. 655-1677, 2015.

[6] K. J. Won, S. H. Kım, E. S. Chung, S. U., Kım and M. W. Son, "Drought Analysis of Cheongmicheon in Korea Based on Various Drought Idices,' in 5. Proceedings of the 3rd International Conference on Civil, Offshore and Environmental Engineering, 2016. pp. 311-315.

[7] M. Fendeková, T. Gauster, L. Labudová, D., Vrablíková, Z., Danáčová, M., Fendek and P. Pekárová, “Analysing 21st century meteorological and hydrological drought events in Slovakia," Journal of Hydrology and Hydromechanics, vol. 66, no. 4, pp. 393-403, 2018.

[8] V. Gümüş, "Hydrological Drought Analysis of Asi River Basin with Streamflow Drought Index, ” GU J Sci, Part C, vol. 5, no.1, pp. 65-73, 2017.

[9] V. Gumus, and H. M. Algin, "Meteorological and hydrological drought analysis of the Seyhan-Ceyhan River Basins, Turkey," Meteorological Applications, vol. 24, no. 1, pp. 62-73, 2017. 
[10] M. Özfidander, D. S. Ucan, F. Topaloglu, "Hydrological Drought Analysis of Streamflow Data in Seyhan Basin," Toprak Su Dergisi, vol. 7, no. 1, pp. 57-64, 2018.

[11] M. S. Yıldız, “Akım Kuraklık İndeksi Yöntemi İle Fırat Havzasının Hidrolojik Kuraklık Analizi,” Harran Üniversitesi Fen Bilimleri Enstitüsü, Yüksek Lisans Tezi, 129 sayfa, 2019.

[12] T. A. Eroglouer, H. Apaydin, "Estimation of Drought by Streamflow Drought Index (SDI) and Artificial Neural Networks (ANNs) in Ankara-Nallihan Region," Turkish Journal of Agriculture - Food Science and Technology, vol. 8, no. 2, pp. 348-357, 2020.

[13] T.C. Bolu Valiliği Çevre ve Şehircilik İl Müdürlüğü. (12 Ağustos 2021). Bolu İli 2019 Yılı Çevre Durum Raporu. Erişim adresi https://webdosya.csb.gov.tr/db/ced/icerikler/bolu_-cdr2019-20200624102754.pdf.

[14] T.C. Tarım ve Orman Bakanlığı Su Yönetimi Genel Müdürlüğü. (12.10.2021). Erişim adresi https://www.tarimorman.gov.tr/SYGM/Belgeler/Türkiye Su Kaynakları Haritas1-07.07.2020/Türkiye Su Kaynakları Haritası.jpg.

[15] I. Nalbantis, I., "Evaluation of a hydrological drought index", Eur Water, vol. 23, no. 24, pp. 67-77, 2008. 